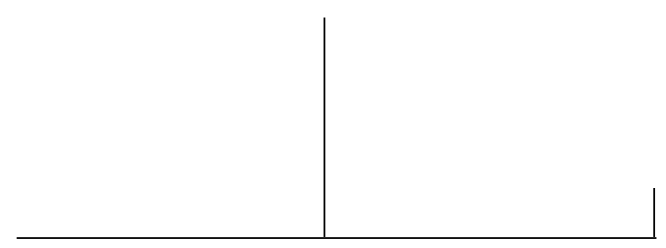

Rev. Latinoam. Psicopat. Fund., São Paulo, v. 12, n. 2, p. 329-341, junho 2009

\title{
Para introduzir a questão da pulsão invocante*
}

Jean-Michel Vives

Neste artigo o autor propõe mostrar como o sujeito nasce na relação com a voz do Outro e como a psique se estrutura em torno de um ponto surdo. Ponto surdo que seria a expressão sonora do recalcamento originário.

É a instauração deste ponto surdo que permitiria ao sujeito se inscrever na dinâmica da invocação e desta forma se inscrever na corrida desejante.

Palavras-chave: Pulsão invocante, voz, grito, recalcamento originário, ponto surdo 


\section{Invocação}

Os psicanalistas abordam pouco a questão da pulsão "invocante". Isso pode parecer surpreendente visto que é essencialmente com essa pulsão que eles trabalham no sigilo de seus consultórios. "Invocante" - ou vociferante, às vezes -: assim a nomeou Lacan, que foi o primeiro a tê-la identificado e isolado como pulsão. Invocare, em latim, remete ao apelo, ao chamamento. O circuito da pulsão invocante se declinará, assim, entre um "ser chamado", um "se fazer chamar" (eventualmente, de todos os nomes...) e um "chamar". Mas, para chamar, é preciso dar voz, depô-la, como depomos o olhar diante de um quadro. Para que isso ocorra, é preciso que o sujeito a tenha recebido do Outro que terá respondido ao grito, que ele terá interpretado como uma demanda. É preciso também que, posteriormente, ele a tenha esquecido, a fim de poder dispor de sua própria voz sem estar saturado da voz do Outro.

Penso que, a partir desse ponto, podemos levantar a hipótese de que a dinâmica do tratamento, no que concerne à pulsão invocante, é caracterizada por uma modificação do lugar do sujeito no circuito da invocação. De fato, ao longo do tratamento, o sujeito que viveu até então, seja submetido ao apelo incondicional do Outro, seja tendo falhado a esse apelo, se descobre igualmente apelante e, consequentemente, desejante. Desse modo, ele entra em uma dinâmica de invocação. Invocação que implica, simultaneamente, o reconhecimento do Outro e de sua falta, que essa ausência na presença seja significável, permanecendo ao mesmo tempo irredutível, é o que Lacan propõe cernir no enigmático S(A barrado), significante da ausência na presença.

Para se compreender a especificidade dessa posição invocante adotada pelo sujeito do inconsciente, é importante situar a diferença essencial que existe entre a demanda e a invocação. Na demanda, o sujeito se encontra em uma posição de dependência absoluta em relação ao Outro, pois ele lhe empresta o poder de atendê-lo ou não. A demanda é compreendida, aqui, como uma exigência absoluta feita ao Outro de se manifestar, aqui e agora. Ao contrário, o sujeito invocante escapa dessa dependência, pois, nesse caso, não se trata mais de uma demanda dirigida a um outro que estaria lá, mas sim de uma invocação que su- 


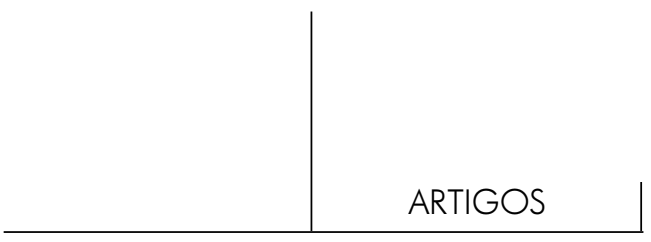

põe que uma alteridade possa advir de onde o sujeito, pura possibilidade, seria chamado a vir a ser. Essa questão da invocação permite-nos repensar os móbeis do sujeito-suposto-saber que nesse processo se torna sujeito-suposto-saber-que-há-sujeito e que, supondo isso, chama-o a advir. A suposição do psicanalista se reduz então - mas nessa redução se condensa toda a ética da psicanálise - ao fato de que, apesar dos sintomas que entravam o paciente, há sujeito que é chamado a ex-sistir.

Para trabalhar essa questão, relatarei rapidamente alguns elementos da história de um jovem, para quem esta dialética do apelo a... e apelo de... ocupa um lugar importante durante os primeiros tempos de sua análise. Étienne veio me consultar após uma tentativa de suicídio que aconteceu em circunstâncias estranhas. Após ter recebido um telefonema de sua mãe, durante o qual mais uma vez ele é o objeto de repreensões severas - "eu fui chamado, diz ele, de tudo quanto é nome" ${ }^{-}$, ele desliga o telefone e se impõe, então, a ele a certeza de que deve pôr fim a seus dias. É o que ele fará, sem que isso o tenha, no entanto, conduzido à morte. Sua companheira o encontrou inconsciente, mas vivo. O que ele pôde dizer sobre as circunstâncias de sua tentativa de suicídio, durante nosso primeiro encontro, foi que ficou sem voz diante da enorme onda de palavras maternas e, fato ainda mais estranho: ele não pôde reconhecer a voz de sua mãe, que lhe parecera estranhamente diferente. Algumas semanas mais tarde, entretanto, ele retificou isso me dizendo: "Eu lhe disse, anteriormente, que não tinha reconhecido a voz dela. Parece-me mais correto dizer que eu ouvi a voz dela, mesmo que eu não saiba muito bem o que quero dizer. Na verdade, ele acrescenta, eu a ouvi de novo, ultimamente, mas dessa vez foi diferente, eu também gritei, xinguei e mais forte que ela!". Na verdade, "a estranha diferença" da voz de sua mãe, percebida por esse paciente, era preferencialmente uma estranha familiaridade (Unheimlich), no sentido em que Freud a analisou em seu artigo de 1919: alguma coisa conhecida, mas que tivesse tido que permanecer dissimulada, velada. $\mathrm{O}$ retorno da voz materna em sua dimensão de objeto $a$ provoca, então, um sentimento de inquietante estranheza.

A certeza de ter que se matar, que se segue ao telefonema materno e que invade Étienne, deve ser considerada como uma manifestação delirante ou não? A questão merece ser colocada, mesmo se a resposta que possamos dar a ela não seja definitiva. Essa questão levanta este problema delicado da afinidade de estrutura entre a alucinação e a instância superegoica em sua dimensão "feroz e obscena". Esse parentesco de estrutura, aliás, não escapou a Freud que, em "So-

1. Em francês, je me suis fait traiter de tous les noms d'oiseaux, literalmente eu fui chamado por todos os nomes de pássaros. (N. da T.)

Rev. Latinoam. Psicopat. Fund., São Paulo, v. 12, n. 2, p. 329-341, junho 2009 


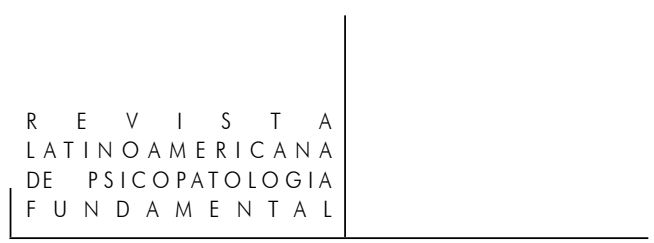

bre o narcisismo: uma introdução", salientava que o sintoma dos delírios paranoides e o das neuroses de transferência têm um ponto comum: uma instância psíquica que "observa ininterruptamente o ego atual e o compara ao ideal (...). Os pacientes se queixam, então, de que conhecemos todos os seus pensamentos, de que observamos e vigiamos suas ações" (Freud, 1914, p.100). Dito de outro modo, o funcionamento do superego não deixa de ter relação com o da alucinação. No caso que nos interessa, esse ponto de junção é particularmente evidente. A partir daí, não penso que a certeza que tomou conta de Étienne seja, essencialmente, delirante, mesmo que ela possa se valer dessa máscara. Na verdade, o paciente do qual falamos aqui não está totalmente invadido pela voz do Outro, visto que ele pode, em um segundo tempo, tentar se subtrair dela vindo se consultar. Essa possibilidade de fuga, de ruptura, parece-me testemunhar que a continuidade monstruosa estabelecida entre a voz do Outro e o mutismo que ela provoca no sujeito permanece sob o ascendente de um significante instaurador de uma possível descontinuidade entre a parte maldita do sujeito (aquilo que do real não poderia caber no simbólico) e a maldição, cuja voz do Outro pode ser o vetor. O sujeito, diante da voz insultuosa do Outro, pode momentaneamente se sentir reduzido ao dejeto evocado e pode tentar fazer de si mesmo um dejeto, mas um certo tipo de relação com o simbólico lhe permite do mesmo modo pressentir que ele não é apenas isso. É este "não apenas isso" que ele vem tentar experimentar no quadro do tratamento psicanalítico.

\section{Revocação}

Não é surpreendente que esse encontro com a dimensão estranhamente inquietante da voz do Outro surja durante um chamado telefônico. De fato, a voz emerge plenamente quando a imagem do locutor se esquiva. O exemplo mais marcante disso é a importância dada à voz do analista, pelo próprio dispositivo do tratamento proposto por Freud. Na verdade, a passagem da hipnose à psicanálise assinala a passagem da sedução ao amor de transferência, a passagem da importância do olhar à sua destituição para que surja uma voz. Como se o saber inconsciente visado pela psicanálise só pudesse se ordenar separado de um "ver demais". Desse modo, Freud só consentiu em se desprender de sua posição de mestre-hipnotizador em uma revocação, submetendo-se à injunção de uma histérica que lhe diz: "Cale-se, escute-me!". Maneira radical de dizer: "Não me dê o que eu te peço, porque não é o que eu desejo". Percebe-se claramente, então, que a apreciação crítica dos móbeis teórico-clínicos da pulsão invocante está no princípio mesmo da conduta do tratamento e estabelecimento do quadro de sua

Rev. Latinoam. Psicopat. Fund., São Paulo, v. 12, n. 2, p. 329-341, junho 2009 
prática. Por essa razão, a situação na qual se encontra implicado Étienne, no momento de sua tentativa de suicídio, é o negativo da situação analítica: ao demasiado pleno da voz materna responde o silêncio do analista, não silêncio mortífero de antes da fala, mas silêncio no qual o sujeito do inconsciente pode supor no Outro o saber de sua possível assunção; à impossibilidade de o paciente falar face às injunções maternas, responde a regra fundamental prescrevendo-lhe dizer, sair de seu mutismo, dar voz.

O suicídio, que no caso desse paciente é a resposta do sujeito ao encontro com a voz do Outro em sua dimensão de apelo incondicional, confronta-nos com uma possível dimensão mortífera da voz materna quando ela se manifesta essencialmente em sua dimensão real, livre de suas amarras simbólicas. Essa voz cativante, que chama a criança e propõe-lhe gozar eternamente da indiferenciação, encontrou através do mito das sereias uma representação. Todo mundo conhece a história desses seres míticos, meio mulheres meio pássaros, que levam à morte os marujos capturados pelas redes de sua voz. Para poder ouvir sem perigo a voz das sereias, no XII canto da Odisseia, Ulisses deverá ser acorrentado ao mastro de seu barco, após ter enchido de cera os ouvidos de seus companheiros e pedir-lhes para não soltá-lo, quaisquer que fossem suas ordens. As sereias dizem a Ulisses: "Venha aqui, venha até nós!... (...)Venha escutar nossas vozes!" (Homère, -800, p. 716). O que importa, realmente no texto é que as sereias são apenas vozes que expressam em sua vocalização um desejo concernente ao sujeito, um apelo incondicional que deixa aqueles que o ouvem sem voz. O que essas vozes veiculam é uma promessa de gozo. Elas remetem o sujeito a um tempo de antes da Lei. Se a voz é aqui, mortífera, é porque a relação com a Lei é salutar para o desejo humano, na medida em que ela permite que a corrida desejante perdure e que não se perca nos reencontros ilusórios. Mas como o homem jamais pode se acomodar totalmente a esta lógica da renúncia, ele sempre se vê tentado por essa voz do gozo que o convida a reatar com o arcaico, com esse tempo mítico em que o desejo não tivera ainda que se atualizar. Aí está a força das sereias, que encontram uma cumplicidade no próprio interior do homem. A voz da sereia, como a da mãe desse paciente, é o desejo do Outro que vem buscar o sujeito e o perde usando seu próprio "tropismo" de gozo: desejo de não desejo, para retomar a fórmula de Piera Aulagnier (Aulagnier, 1975). Ao passo que a voz enquanto tal desaparece por detrás da significação no ato de fala, na sereia ela ocupa a frente da cena como pura materialidade sonora. Tornando-se real, próxima do grito, ela berra para quem quiser ouvi-la: "Goze, nós lhe ordenamos! Que nada o detenha! Para você, o saber absoluto!".

Encontramos aqui uma das expressões clínicas deste superego "feroz e obsceno", que pode incitar o sujeito a se anular no gozo. Lacan formulava assim a 


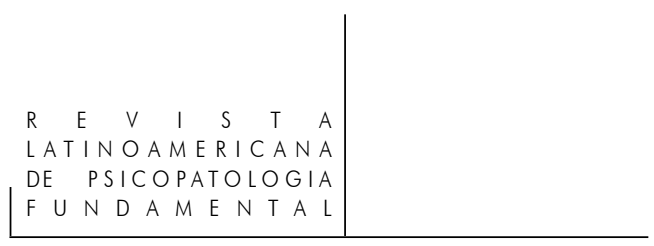

imposição superegoica: "O superego é o imperativo do gozo - goze!" (Lacan, 1972 , p. 10). No caso em questão, o ego, acuado pela pressão vocal superegoica, chega a cometer, contra ele, atos de uma violência rara. O suicídio representa, então, a saciedade parcial no caminho que conduz o sujeito em direção à miragem de um possível gozo sem limite. Compreende-se a partir daí, como Freud escreveu (Freud, 1923), que, em certas situações, possa reinar no superego uma pura cultura da pulsão de morte. Aqui, o estofo desse superego se reduz a um pedaço de voz liberado de suas amarras simbólicas, bastante próximo desse objeto errático nomeado na teoria lacaniana de objeto $a$.

Diante dessa injunção, esse paciente fica sem voz, mergulha em um silêncio que qualificaremos, com Alain Didier-Weill (1995), como silêncio do abismo. Abismo que, contrariamente às trevas que são arrancadas do silêncio pelo "Fiat lux" que as nomeia e as transforma em "noite", designa um ponto de real que nenhuma nominação virá içar, ulteriormente, à existência. Silêncio mortífero, presença absoluta que ainda não teria conhecido a ruptura da pulsação criada pela alternância presença/ausência. É o infans - aquele que ainda não tem acesso à fala - que se encontra aqui convocado por esse silêncio. O paciente em mutismo diante dessa voz arcaica encontra no pedido de socorro dirigido ao psicanalista uma primeira possibilidade de gerir a situação fora da passagem ao ato suicida. No momento em que ele ouvir de novo esta voz, agora, ele "berrará", o que lhe permite, como um novo Orfeu, abafar com seu canto a voz das sereias. Conhecemos a lenda dos Argonautas que embarcaram para conquistar o velocino de ouro sob o comando de Jasão. Esse herói pediu ao poeta-cantor para acompanhá-lo com a finalidade de tornar seus companheiros surdos às vozes perniciosas das sereias. Foi o que ele fez. Essa lenda nos mostra como o canto (mistura de voz e linguagem) é o que faz calar a voz ou, pelo menos, ficar surdo a ela. O canto não é, a partir daí, o que permite melhor exemplificar a voz como objeto. Ele é, no máximo, a revocação da voz, aquilo que permite mantê-la à distância. Ele é um domador de voz, como o quadro é, segundo Lacan, um domador de olhar. (Lacan, 1964). O que leva Jacques-Alain Miller (1989) a dizer: "Se nós falamos tanto, se fazemos nossos colóquios, se conversamos, se cantamos e se ouvimos os cantores, se fazemos música e se as escutamos (...) é para fazer calar o que merece que se chame a voz de objeto $a$ " (p. 184). Assim, quando a voz vem se desvelar como apelo ao qual nada pode responder, o sujeito é então confrontado com o real. Ele pode, então, escolher ou caber [échoir] no simbólico "abrindo sua boca", como dizia meu paciente, ou decair [déchoir] no real tornando-se o "lixo", o "dejeto", "a merda", usando as palavras de um outro paciente, que ele acredita ter que ser para se submeter ao que ele interpreta como sendo o desejo do Outro. 


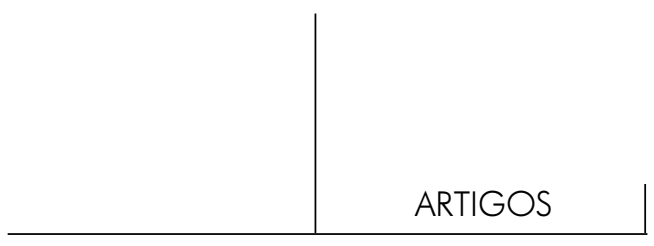

Convocação

Ao se conferir à invocação, como ao olhar, o estatuto de pulsão, Lacan propõe uma nova dialética das pulsões. Junto ao objeto oral e ao objeto anal, articulados à demanda - o objeto oral está associado à demanda ao Outro, o objeto anal à demanda do Outro -, ele introduz o olhar e a voz que concernem ao desejo o olhar está associado ao desejo ao Outro, a voz ao desejo do Outro.

A voz que vem do outro é a manifestação de seu desejo, é igualmente o desejo que se tem dele, o que leva Lacan a dizer (1966):

O objeto $a$ está diretamente implicado quando se trata da voz e isso no nível do desejo. Se o desejo do sujeito se funda como desejo do Outro, esse desejo como tal se manifesta no nível da voz. A voz não é somente o objeto causal, mas o instrumento pelo qual se manifesta o desejo do Outro. Esse termo está perfeitamente coerente e constitui, se posso dizer, o ponto culminante em relação aos dois sentidos da demanda, seja ao Outro, seja vinda do Outro. (inédito)

Nessa citação, Lacan utiliza o termo demanda, mas penso que, a partir da distinção proposta no início entre demanda e invocação, o termo invocação seria aqui mais adequado. De fato, a voz é um objeto totalmente particular na lista dos objetos pulsionais, pois ela concerne menos à demanda que ao desejo do Outro. A demanda do Outro concerne ao objeto anal. Certamente, a voz pode ser analisada, como o mostram a relação existente entre certos amantes de ópera e as fitas cassetes, nas quais eles tentam conservar de modo ciumento as vozes roubadas durante as apresentações. Mas esta dejetização da voz é apenas o último caso. De fato, ao seio, ao excremento e ao olhar que parcializam o corpo, opõe-se a voz que, ela, subjetiva. Pela sua musicalidade, ela é o meio pelo qual a linguagem e a fala se transmitem. Para demonstrar isso, parece-me necessário retornar uma vez mais a este instante mítico do nascimento do sujeito, enfatizando, aqui, o papel da voz do Outro.

Nos primórdios de sua existência, sob efeito de uma tensão endógena impossível de ser gerida pelo infans por causa de sua prematuridade, este solta um grito. A princípio, o grito do recém-nascido não é apelo ou chamamento, mas somente expressão vocal de um sofrimento. Ele só se tornará apelo pela resposta da voz do Outro, em que se inscreve seu desejo: "O que você quer que eu queira de você?". O sujeito é aqui chamado a ser. Ou seja, ele não é um produto natural. Para que ele exista é preciso que o Outro o chame (no sentido duplo de apelo ou chamamento e de nominação). Pela invocação do Outro, o significante entra no real e produz o sujeito enquanto efeito de significação, à guisa de resposta. Com a resposta do Outro, o grito puro [pur] se tornará grito para [pour]. É a voz do Outro que vai introduzir o infans na fala e fará com que ele perca para

Rev. Latinoam. Psicopat. Fund., São Paulo, v. 12, n. 2, p. 329-341, junho 2009 


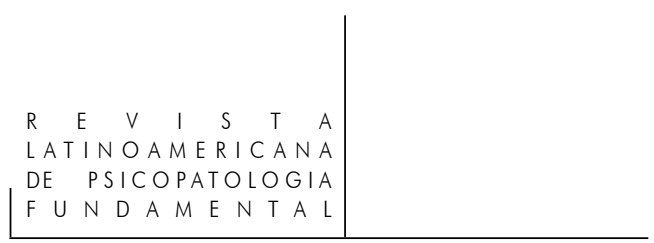

sempre o imediatismo da relação com a voz enquanto objeto. A materialidade do som será, a partir daí, irremediavelmente velada pelo trabalho da significação. A palavra faz calar a voz. A linguagem perfura o corpo, marca o vivo e implica a apropriação do sujeito pela linguagem e não o contrário. Nessa medida, esse velamento da voz não permanecerá sem consequência, já que é ele que permitirá que o sujeito advenha. De fato, sem esse primeiro velamento, nenhuma possibilidade para o sujeito de dar voz, submisso que ele é às ferozes injunções da voz do Outro que ele percebe então no real. Dizendo de uma maneira mais abrupta, a voz do Outro invoca o sujeito, sua fala o convoca. É numa certa despossessão de seu grito, que o infans simultaneamente perde e encontra sua voz. A partir daí, a voz é este real do corpo que o sujeito consente perder para falar, ela é este "objeto caído do órgão da fala" (Lacan, 1963, p. 84).

Deste modo, o circuito da pulsão comporta dois tempos:

- O Outro responde ao grito do infans e o chama a advir como sujeito, supondo-o: "Torne-se!".

- A partir daí, o infans não terá mais acesso diretamente à materialidade vocal que permanecerá, no melhor dos casos, velada por detrás do processo de significação. A busca da voz como objeto pode então se engatar. O infans, ao perder a voz como objeto, torna-se invocante, dá início a seu processo de subjetivação e engata sua corrida desejante: "Volte!".

Ao longo desse encontro entre a palavra do Outro, sustentada por uma voz, e o grito do infans, é transmitida, por um lado, uma lei simbólica fundada nas escansões próprias à linguagem, e, por outro lado, e ao mesmo tempo, age algo contrário à lei, uma subversão dessa lei. Na verdade, a pura continuidade está sempre agindo no cerne mesmo da fala. Continuidade produzida pela voz da mãe e que mina sua fala à qual o infans foi confrontado, mas também pura continuidade do grito do infans - aqui a diferenciação entre a voz do infans e a da mãe é vã -, que tende a abolir a descontinuidade ao transmitir a inteligibilidade do sentido. Diante dessa continuidade, para advir, o infans deverá poder se tornar surdo. Ele deverá poder permanecer surdo ao canto da sereia, para ouvir somente o canto da poetisa que o convida a se advir. Esta surdez criará no interior da psichê aquilo que proponho chamar de ponto surdo. Ponto surdo - no sentido em que falamos de ponto cego em relação à visão - que definirei como o lugar no qual o sujeito, para advir como falante, deve, enquanto emissor por vir, poder esquecer que ele é receptor do timbre originário. Ele deve poder ensurdecer-se para o timbre primordial, para falar sem saber o que diz, quer dizer, como sujeito do inconsciente. Para se tornar falante, o sujeito deve adquirir uma surdez específica para com este outro que é o real do som musical da voz. Da mesma maneira que um pon- 
to cego estrutura a visão, a aquisição de um ponto surdo - adquirido pelo recalcamento originário - se mostra necessária para se poder ouvir e falar. Levanto a hipótese de que esta surdez estrutural é aquilo que nos protege da alucinação auditiva. O sujeito que era invocado pelo som originário vai se tornar, através da fala, aquele que invoca. Nessa reviravolta, ele vai conquistar sua própria voz. Para que ele possa se fazer ouvir, é preciso que ele pare de escutar a voz originária: é preciso que ele conquiste um ponto de surdez que lhe permitirá paradoxalmente invocar, ou seja, supor que há um não surdo para ouvi-lo. Para se tornar falante, o sujeito se constitui como um esquecido da voz do Outro. Nessa medida, esse esquecimento não é uma foraclusão: se o sujeito teve radicalmente que esquecer a "mensagem" do som originário, ele não esqueceu o ato que fez dele um esquecido. A voz primordial se tornou "inaudita". É nesse ponto surdo que a pulsão invocante procede à subjetivação do infans: o infans deve permanecer surdo ao apelo da voz do Outro, mas é esse excesso mesmo, ao trabalhar e minar sua fala, que permitirá o seu investimento. Dito de outro modo, é justo pelo fato de haver um móbil de gozo na tomada de fala que esta pode ser investida apesar de seus grandes inconvenientes que são o mal-entendido e a maldição.

Sem esse ponto de gozo ligado ao aquém da fala que é a voz, nenhuma assunção sonora do sujeito é possível. Após ter feito ressonância ao timbre do Outro e tê-lo, ao longo do processo do recalcamento originário, ao mesmo tempo assumido (Bejahung) e rejeitado (Ausstossung), o sujeito deverá poder tornar-se surdo para ele para fazer soar seu próprio timbre. Assim, em um segundo tempo, a voz do sujeito como enunciação se apoiará nessa possibilidade de ter ficado surdo a essa voz. Nessa medida, o princípio mesmo da pulsão invocante mostra que o sujeito do inconsciente não esqueceu que, para se tornar invocante, teve que se ensurdecer para a pura continuidade vocal do Outro.

Desse modo, a operação do recalcamento originário permite à voz permanecer em seu lugar, isto é, inaudível num primeiro tempo e, depois, inédita. Esta surdez para a voz primordial permitirá ao sujeito vir, por sua vez, a dar voz.

\section{Evocação}

Aquele que não terá podido estruturar, por intermédio do recalcamento originário, esse ponto surdo se verá invadido pela voz do Outro. Aquele que não terá conseguido tornar-se surdo para essa voz primordial ficará para sempre pendurado nela e em sofrimento. Essa voz que o sujeito não pode fazer calar, pois ela não fala, foi imaginarizada sob a forma das imprecações das Erínias, que não dizem nada, mas perseguem o sujeito com seus terríveis gritos inarticulados. Voz 


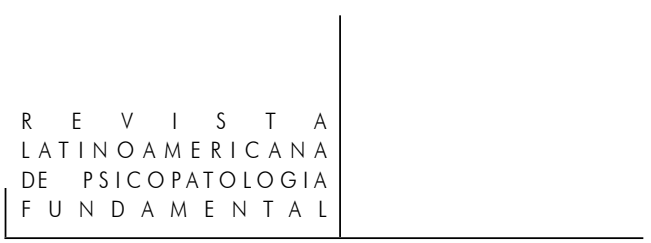

do gozo, que Lacan (1963) aproxima do estertor de gozo e da morte do pai da horda primitiva.

Essa voz arcaica conhecerá um duplo destino, como nos descreve o texto freudiano sobre a denegação (Freud, 1925). Pelos mecanismos de introjeção (introjizierien) e de rejeição (werfen), uma clivagem radical, submetida ao funcionamento do princípio de prazer, é efetuada entre o bem e o mau. Todo o bom é introjetado para o interior, todo o mau rejeitado para o exterior, o que implica que aquilo que foi rejeitado (werfen) foi primeiramente reconhecido como me pertencendo. Mas ao mesmo tempo, um mecanismo completamente diferente, não totalmente submetido ao princípio de prazer, por intermédio do par afirmação-expulsão (Bejahung-Ausstossung), permite instaurar uma relação com o mundo, na qual não se trata mais de dois Outros (um bom e um mau) e sim de um único, clivado.

Esse duplo tratamento estará, por um lado, na origem do supereu - trata-se da primeira parte do circuito da pulsão invocante: o Outro se endereça ao sujeito, mas o sujeito é incapaz de fazer o que quer que seja com esse endereçamento - e, por outro lado, permitirá a emergência da voz do sujeito, na medida em que, para poder ter uma voz, ele teve que perder a do Outro após tê-la aceitado.

Então, por um lado, a voz será rejeitada (werfen) e poderá conhecer o destino de um objeto errático, uma voz fantasma. Essa parte real, não simbolizada, vai subsistir enquanto pai morto, infatigável e ameaçador. Isso constituirá as vozes loucas e violentas da consciência sobre a qual Freud (1912), em "Totem e tabu", diz: "A consciência moral é a percepção interna da rejeição (Verwerfung, no texto) de moções de desejo particulares que existem em nós; mas a ênfase incide no fato de que essa rejeição não precisa se referir a nada, ela está certa de si mesma" (p. 275-276). Hipótese pouco explorada, mas particularmente fecunda, como mostra Alain Didier-Weill (1995), que me leva a compreender que uma foraclusão (o termo utilizado por Freud em "Totem e tabu" é Verwerfung, parece-me então justificável falar de foraclusão) primordial em relação à voz arcaica retorna como "percepção interna" - o termo aqui é também de Freud - desse algo déjà entendu (já ouvido) que é a voz da consciência. Através dessa "percepção interna", o sujeito que acede ao real sem mediação significante vive a experiência mortífera do mundo de iniquidade, que é um mundo sem lei: a lei é, de fato, a introdução de um significante da alteridade que, ao se interpor entre o real e o sujeito, tem como efeito interditar o real de se oferecer à percepção interna do sujeito, simbolizando-se em um dizer. Nessa medida, nem tudo do real pode ser tomado em conta pelo simbólico. É desse modo que aquilo que da voz arcaica foi subtraído do poder simbolizante da interdição retorna no real. De fato, habitando no simbólico, o significante nunca está lá onde o esperávamos, como o 
mostra o chiste e, no melhor dos casos, a interpretação. Ao passo que habitando no real ele já está lá desde sempre, como nos ensina a experiência unheimlich, estranhamente inquietante do "nunca-e-no-entanto-já-ouvido" expresso por Étienne. Esta parte real da voz, incorporada durante a identificação primeira com o pai arcaico, é o elemento constitutivo do supereu "feroz e obsceno". Quando essa voz do pai arcaico não é pacificada, ela persegue o sujeito com suas injunções terríveis. É o que nos mostra, de uma maneira especialmente dramática, a clínica da psicose: pacientes que vagam pelos hospitais com a orelha colada em um rádio, para tentar encobrir suas/essas vozes.

O outro destino da voz do pai será, graças ao tratamento pelo par Bejahung-Ausstossung, constitutivo do sujeito do inconsciente. A diferença fundamental entre o funcionamento do par introjizierien-werfen e o par Bejahung-Ausstossung é que o primeiro visa colocar em perspectiva um limite entre o simbólico e o real, enquanto o segundo visa produzir uma continuidade moebiana entre o simbólico e o real. A assunção pela qual o sujeito diz "sim" (Bejahung) à voz originária implica que ele pague com sua pessoa para que possa surgir, por um movimento de negativização (Ausstossung) dessa voz, uma voz Outra que ele possa usar. Dito de outro modo, o sujeito deve, após tê-la aceito, poder esquecer - sem que haja esquecimento do ato de esquecimento - a voz originária, para falar sem saber o que diz, ou seja, como sujeito do inconsciente. Aqui se nodula, em sua dimensão subjetivante, a pulsão invocante da qual Lacan (1964) pôde dizer várias vezes que ela era "a mais próxima da experiência do inconsciente" (p. 96).

\section{Referências}

Aulagnier, P. La violence de l'interprétation. Paris: PUF, 1975.

Didier-Weill, A. Les trois temps de la loi. Paris: Seuil, 1995.

Freud, S. (1912). Totem et tabou. In: Oeuvres Complètes. Paris: PUF, 1998. tome 11. . (1914). Pour introduire le narcissisme. In: La vie sexuelle. Paris: P.U.F., 1982. p. $81-105$.

. (1919). L'inquiétant. In: Oeuvres Complètes. Paris: PUF, 1996. tome 15, p. 147-

188.

. (1923). Le Moi et le Ça. In: Oeuvres Complètes. Paris: PUF, 1991. tome 16, p. 255-301.

(1925). La négation. In: Oeuvres Complètes. Paris: PUF, 1992. tome 17, p. 165-

171.

Rev. Latinoam. Psicopat. Fund., São Paulo, v. 12, n. 2, p. 329-341, junho 2009 
HoMÈre (- 800 av J.C.). L'Odyssée. Paris: Gallimard,1953. p. 561-878.

LACAN, J. (1962-1963). Le séminaire. Livre X. L'angoisse. Paris: Seuil, 2004.

. (1963). Introduction aux Noms-du-Pères. In: Des Noms-du-Père. Paris: Seuil, 2005. p. 65-104.

. (1964). Le séminaire. Livre XI. Les quatre concepts fondamentaux de la psychanalyse. Paris: Seuil, 1973.

. (1966). Le séminaire. Livre XIII. L'objet de la psychanalyse. inédit. . (1972-1973). Le séminaire. Livre XX. Encore. Paris: Seuil, 1975.

MitLer, J.A. Jacques Lacan et la voix. In: La voix. Paris: La Lysimaque, 1989. p. 175184.

\section{Resumos}

(Para introducir la cuestión de la pulsión invocante)

El autor se propone en este artículo mostrar cómo el sujeto nace en relación con la voz del Otro y cómo la psique se estructura en torno de un punto sordo. Ese punto sordo sería la expresión sonora de la represión originaria.

Es la instauración de ese punto sordo lo que permite al sujeto inscribirse en la dinámica de la invocación y de esa forma también inscribirse en la corrida deseante.

Palabras claves: Pulsión invocante, voz, grito, represión originaria, punto sordo

(Pour introduire la question de la pulsion invocante)

Le but de cet article est de montrer comment le sujet naît dans le rapport avec la voix de l'Autre et comment la psyché se structure autour un point sourd. Point sourd qui serait l'expression sonore du refoulement originaire. C'est l'instauration de ce point sourd qui permettrait au sujet de s'inscrire dans la dynamique de l'invocation et donc de s'inscrire dans la course désirante.

Mots clés: Pulsion invocante, voix, cri, refoulement originaire, point sourd

(Introducing the question of the pulsating invocative drive)

In this article the author endeavors to show how the mental apparatus develops a structure around a "deaf spot," understood as the expression of primal repression. The establishment of this "deaf spot" allows the subject to be inscribed in the dynamics of invocation and therefore be inscribed in the world of desire.

Key words: Invoking drive, voice, cry, primal repression, deaf point 


\section{ARTIGOS}

Citação/Citation: VIVES, J.-M. Para introduzir a questão da pulsão invocante. Revista Latinoamericana de Psicopatologia Fundamental, São Paulo, v. 12, n. 2, p. 329-341, jun. 2009.

Editor do artigo/Editor: Prof. Dr. Manoel Tosta Berlinck.

Recebido/Received: 9.3.2008/3.9.2008 Aceito/Accepted: 20.4.2008/4.20.2008

Copyright: () 2009 Associação Universitária de Pesquisa em Psicopatologia Fundamental/ University Association for Research in Fundamental Psychopathology. Este é um artigo de livre acesso, que permite uso irrestrito, distribuição e reprodução em qualquer meio, desde que $\mathrm{o}$ autor e a fonte sejam citados/This is an open-access article, which permits unrestricted use, distribution, and reproduction in any medium, provided the original author and source are credited.

Financiamento/Funding: $\mathrm{O}$ autor declara não ter sido financiado ou apoiado/The author has no support or funding to report.

Conflito de interesses: $O$ autor declara que não há conflito de interesses/The author declares that has no conflict of interest.

\section{Jean-Michel Vives}

Professeur de Pychopathologie clinique Université de Nice Sophia Antipolis; psychanalyste. 90 Chemin Beau Site

83100 Toulon - France

Tel : 0494424497 -

e-mail: vives@unice.fr 